\title{
Idiopathic aneurysm of the pulmonary artery trunk. case report
}

\begin{abstract}
Summary
The pulmonary artery aneurysm (AAP) are uncommon, if they breakthey have highmortalitythat's whythey identification and stratification is necessary. They can be acquired, congenitaland rarely idiopathic. Its clinic spectrumcomes sinceasymptomaticwith an accidentally discovery in the chest X-ray, dyspnea, hemoptysis, chest pain or sudden death in case of rupture. It reportsthe sixty-two years woman case, with an incidental diagnosticof Pulmonary Artery Aneurysm ofIdiopathic etiologyanditsdiagnostic andtherapeutic approach.
\end{abstract}

Keywords: pulmonary artery aneurysm, idiopathic, tomographic angiography
Volume 9 Issue 4 - 2017

\author{
Luis Lopez Luis Rey,' Gutiérrez Galvan Maraí \\ Xochitl,' Sarmiento Muñoz Victor Ignacio,' \\ Gonzalez Ortiz Horacio, ${ }^{2}$ Hernández- \\ González Martha Alicia ${ }^{2}$ \\ 'Department of Cardiology, High Specialty Medical Unit Baj \\ ${ }^{2} \mathrm{Head}$ of Health Research Division, Medical Unit of High \\ Specialty No. I Hospital of Specialties National Medical Center \\ Mexico
}

\begin{abstract}
Correspondence: Martha Alicia Hernández González, Head of Health Research Division, High Specialty Medical Unit No. I Hospital of Specialties National Medical Center, IMSS. Leon, Guanajuato, Mexico, Tel (52) 477 7174800, Email Martha.hernandezg@imss.gob.mx
\end{abstract}

Received: August 04, 2017 | Published: August 16, 2017

\section{Clinical case}

Sixty-two years woman, hypertensive, without any other precedent. Asymptomatic, in functional class I of the NYHA. Ingressbyan accidentally discovery in thorax radiography of volume increase in the pulmonary cone. It feel Thrill in the $2^{\circ}$ left intercostal space in parasternal line, mate the percussion of $2 \mathrm{~cm}$ of diameter, mesotelesystolicmurmurin the pulmonary focus, of soft tonality, intensity III/VI, without irradiations, with $2^{\circ}$ firm sound; normal peripheral pulses, no cyanosisnordigital clubbing.The rest of the exploration is normal.

Chest x-ray without cardiomegaly, with prominent pulmonary artery cone; Electrocardiogram in sinus rhythm, normal; Transthoracic echocardiogram with aneurysmal dilatation of the pulmonary artery trunk (TAP), maximum diameter of $60 \mathrm{~m}$, extending to the emergency of the left branch with a diameter of $37 \mathrm{~mm}$, pulmonary artery systolic pressure of $30 \mathrm{mmHg}$, wall thickness of the right ventricle of the right ventricle $10 \mathrm{~mm}$ without pulmonary valvular pathology; In the Angiotomography the TAP dilatation of $58 / 67$ / 63mm is corroborated, in the proximal,mid and distal segments, extending to the left main branch with a diameter of $35 \mathrm{~mm}$. Tests of renal, hepatic and thyroid function were normal; Autoimmune markers (antinuclear antibodies, anti-Sm antibodies and anti-DNA antibodies), antistreptolysin $\mathrm{O}$, rheumatoid factor, VDRL and C-reactive protein, all of them were negative; Serology for Rubella, Toxoplasma, Mononucleosis, Brucella, Chlamydia, Aspergillus fumigatus and Candida were negative; Negative blood culture; Tumor markers Ca 19-9, Ca 125, Carcinoembryonic Antigen and Alpha Fetoprotein were normal. The existence of vasculitis or Marfan syndrome was dismissed, so it was concluded that it is idiopathic. Only medical surveillance is decided. The patient remained asymptomatic and unchanged in the TAP dimensions by echocardiogram at three months of follow-up.

\section{Discussion}

Pulmonary artery aneurysms (AAP) are rare, 1 per 14,000 autopsies, where the prognosis is fatal in the event of rupture.The normal upper limit of the TAP diameter is $28 \mathrm{~mm}$ and the interlobar artery $17 \mathrm{~mm} ; 40 \mathrm{~mm}$ is considered an aneurysm and its most frequent location is in the TAP with or without involvement of the main branches, or with extension to the left branch. ${ }^{1,2}$
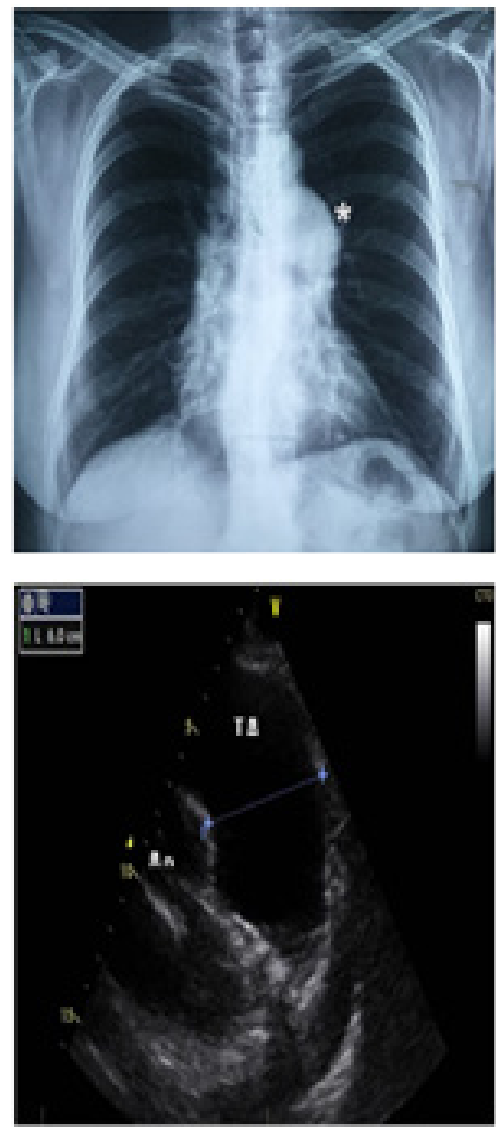

Figure I X-Ray and Echocardiography image correlation. 

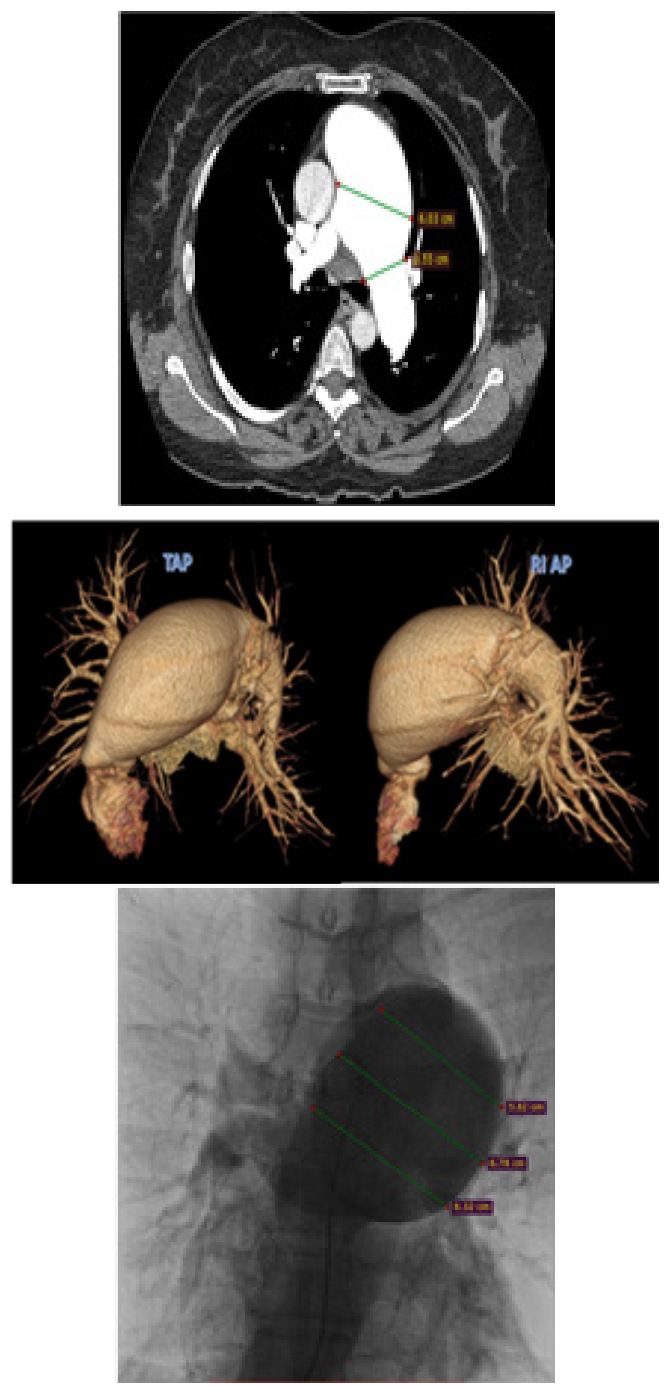

Figure 2 Angiotomographyc 3D reconstruction and angiogram correlation. Pulmonary trunk of $60 \mathrm{~mm}$ and left artery pulmonary $35 \mathrm{~mm}$.

Its etiology is divided into congenital, acquired (connective tissue diseases, infections and trauma) and a small percentage is diagnosed by exclusion as idiopathic. The clinical spectrum may be asymptomatic as a casual finding, or present with dyspnea, hemoptysis and chest pain. ${ }^{3}$ The complications that may occur are the compression of nearby structures (bronchus or left coronary artery), intraarterial thrombosis, dissection or rupture of AAP where its most evident clinical manifestation is massive hemoptysis or sudden death.

Surgery is indicated when there is a history of hemoptysis that speaks of dissection or rupture, or when the diameter of the pulmonary artery is greater than $60 \mathrm{~mm}$. There are still controversies regarding conservative treatment. It is generally accepted to correct the underlying cause, but in the idiopathic asymptomatic subjectlike this case,only medical surveillance with emphasis in the measurement of the diameter of the pulmonary artery by echocardiography, twice a year, is necessary. ${ }^{4}$

\section{Conclusion}

Idiopathic AAPs are very rare, it is generally accepted that in asymptomatic patients with a diameter of less than $60 \mathrm{~mm}$, normal pulmonary pressure, absence of congenital or acquired shuntsproved by echocardiogram are considered low-risk and conservative behavior is chosen, as was our case.

\section{Acknowledgments}

The authors acknowledge to Ramon Humberto Solorio Hernández, his writing assistance, technical editing and language editing.

\section{Conflicts of interest}

Author declares there no conflicts of interest.

\section{Funding}

None.

\section{References}

1. Hayoun C, Alonso Charterina S, Sanchez-Nistal MA. Aneurismas de la arteria pulmonar: Aportacion de la TCMD en el diagnóstico diferencial y complicaciones. SERAM, S-0766. 2012.

2. Martinez-Quintana E, Rodriguez-Gonzalez Gomez-Guindal JA, Junquera-Rionda P. Aneurisma idiopatico de la arteria pulmonar principal en paciente joven, Radiologia. 2010; 52:255-257.

3. Moreno R, Calvo L, García E, et al. Hipertrofia septal severa: ¿es necesariamente una contraindicacion para la implantacion transcateter de prótesis de Edwards-Sapien?, Rev Esp Cardiol. 2010;63:241-242.

4. Palma-Nieto JC, Anton-Martinez J, Ramos-del Amo VM, et al. Aneurisma de la arteria pulmonar. Presentacion de un caso, Rev Esp Cardiol. 1999;52:148-150. 